\title{
Processing and Properties of PCL/Cotton Linter Compounds
}

\author{
Elieber Barros Bezerra ${ }^{a}$, Danyelle Campos França ${ }^{a}$, Dayanne Diniz de Souza Morais ${ }^{a}$, Morsyleide de \\ Freitas Rosa ${ }^{b}$, João Paulo Saraiva Morais ${ }^{b}, E_{\text {Edcleide Maria Araújo }}^{a}$, Renate Maria Ramos Wellen * \\ ${ }^{a}$ Materials Engineering Department, Federal University of Campina Grande - UFCG, Campina \\ Grande, PB, Brazil \\ ${ }^{b}$ Embrapa Tropical Agroindustry, Fortaleza, CE, Brazil \\ ${ }^{c}$ Materials Engineering Department, Federal University of Paraíba - UFPB, João Pessoa, PB, Brazil
}

Received: February 1, 2016; Revised: September 4, 2016; Accepted: December 13, 2016

\begin{abstract}
Biodegradable compounds of poly( $\varepsilon$-caprolactone) (PCL)/ cotton linter were melting mixed with filling content ranging from $1 \%$ to $5 \% \mathrm{w} / \mathrm{w}$. Cotton linter is an important byproduct of textile industry; in this work it was used in raw state and after acid hydrolysis. According to the results of torque rheometry no decaying of viscosity took place during compounding, evidencing absence of breaking down in molecular weight. The thermal stability increased by $20 \%$ as observed in HDT for $\mathrm{PCL} /$ cotton nanolinter compounds. Adding cotton linter to PCL didn't change its crystalline character as showed by XRD; however an increase in degree of crystallinity was observed by means of DSC. From mechanical tests in tension was observed an increase in ductility of PCL, and from mechanical tests in flexion an increase in elastic modulus upon addition of cotton linter, whereas impact strength presented lower values for PCL/cotton linter and PCL/cotton nanolinter compounds. SEM images showed that PCL presents plastic fracture and cotton linter has an interlacing fibril structure with high L/D ratio, which are in agreement with matrix/fibril morphology observed for PCL/cotton linter compounds. PCL/cotton linter compounds made in this work cost less than neat PCL matrix and presented improved properties making feasible its commercial use.
\end{abstract}

Keywords: Poly(E-caprolactone) (PCL), cotton linter, compounds, processing, mechanical properties.

\section{Introduction}

Synthetic plastics have been used for various purposes, especially in the packaging, automotive, and health care industrial sectors. However, the majority of these materials constitute at present a serious waste management problem. Biodegradable polymers have attracted special attention as the plastics of the $21^{\text {st }}$ century, since they can be biologically degraded and therefore can be considered as environmental friendly materials ${ }^{1-3}$. Biodegradable polymers are by definition those that degrade as a result of the action of microorganisms and/or enzymes. They are a specific type of polymer that breaks down after its intended purpose to result in natural byproducts such as gases $\left(\mathrm{CO}_{2}, \mathrm{~N}_{2}\right)$, water, biomass and inorganic salts. These polymers are found both naturally and synthetically made ${ }^{4-6}$.

PCL is a linear aliphatic semicrystalline polyester, synthesized by ring-opening polymerization of the cyclic lactone in presence of a catalyst. PCL is a polymer with good ductility because of its low glass transition temperature of $-60^{\circ} \mathrm{C}$. Due to its biodegradability, biocompatibility and environmental friendliness PCL has been used for packaging, agriculture and medical devices, as well as a substitute of non-biodegradable commodity polymers ${ }^{7-9}$.

Cotton linter is a widely available, renewable, low cost, and biodegradable reinforcement. It is an important byproduct of the textile industry, composed of short fibers that cling to cottonseeds after the first ginning. The fuzzy seed needs to be subjected to an additional process that will mechanically remove the linter. The amount of linter produced worldwide is around 2.5 million metric tons, considering the 42 million metric tons of cotton lint produced in 2010. Traditional products made from linter are: absorbent cotton, special papers, cellulose nitrate, and acetate. In some cases, the linter is not extracted, but kept with the seed (when it is used for oil extraction) or chemically dissolved (for planting the seed) $)^{10-13}$.

PCL is a commercial polymer, fully biodegradable and biocompatible, and cotton linter is an inexpensive biodegradable filler regionally available. Thus, $\mathrm{PCL} /$ cotton linter compounds may be of interests as an environmentally-friendly substitute of material currently used in many applications. 
In this work PCL/cotton linter compounds were melt extruded and test samples injected with filling content ranging from $1 \%$ to $5 \%$ of the weight.

The main objective of producing PCL/cotton linter compounds was to make a material $100 \%$ biodegradable using as filling a regional byproduct, costing less than neat PCL matrix, with similar processing conditions and the same machinery.

Properties and morphology of neat PCL and its compounds were investigated by means of torque rheometry, heat deflection temperature (HDT), thermogravimetry (TG), differential scanning calorimetry (DSC), X ray diffraction (XRD), scanning electron microscopy (SEM), mechanical tests in tension, flexion and impact.

This paper presents as novelty the use of cotton linter and nanoliter, which are byproducts of the cotton culture, as filling for PCL compounds. According to the results forward presented these compounds have improved thermal stability and mechanical properties, costing less than neat PCL. It is also worth mentioning that the use of cotton linter is an income source for the poor population in the northeast region of Brazil.

\section{Experimental}

\subsection{Materials}

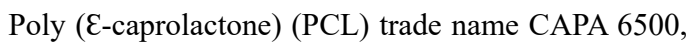
with molar mass (M) $47500 \mathrm{~g} / \mathrm{mol}$ and viscosity (ๆ) 2890 Pa.s $\left(70^{\circ} \mathrm{C}, 101 . \mathrm{s}^{-1}\right)$ was purchased from Perstork.

Raw cotton linter was kindly supplied by Embrapa Cotton, Campina Grande/Paraíba/Brazil. It was obtained from cotton Delta Opal, harvested in State of Bahia, Brazil, 2010, under environmental conditions of the cerrado (Brazilian savannah).

Cotton nanolinter was produced by acid hydrolysis of raw cotton linter. The acid hydrolysis procedure used to make the nanolinter is described in Morais et al (2013) ${ }^{14}$. It was kindly supplied by Embrapa Tropical Agroindustry, Fortaleza/Ceará/ Brazil. It is expected that the use of nanoparticulate filler will improve the performance of the compound compare with the conventional micro compound, i.e. untreated cotton linter.

Figure 1 shows cotton linter and cotton nanoliter samples used to prepare PCL compounds.

\subsection{Methods}

\subsubsection{Improvement of raw cotton linter}

As received raw cotton linter was washed several times in a decantation apparatus connected to a compressor (at 3 Bar) to take off the impurities, and then it was brushed and used to make the PCL compounds, processing occurred at room temperature.
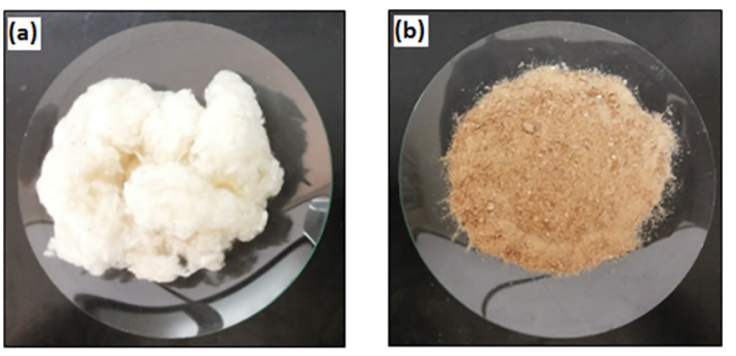

Figure 1: Cotton linter (a) and nanolinter (b) as used to make PCL compounds.

\subsubsection{Processing}

Concentrates of 95/5 PCL/cotton linter and 95/5 PCL/ cotton nanolinter were made by melt mixing in a thermokinetic mixer model $\mathrm{MH}-50 \mathrm{H}$; and ground in a knife mill. The concentrates were diluted to final cotton linter and cotton nanolinter concentrations of $1 \%, 3 \%$ and $5 \% \mathrm{w} / \mathrm{w}$ with neat PCL in a corotating twin screw extruder CoperionWerner\&Pfleiderer ZSK 18 operating at $80-90^{\circ} \mathrm{C}$ and 180 $\mathrm{rpm}$, followed by grinding in a knife mill. Same procedure was applied to neat PCL.

Specimens of PCL/cotton linter and PCL/cotton nanolinter at 99/1, 97/3 and 95/5 w/w for tensile, impact, flexion, and heat deflection temperature testing according to ASTM D638, ASTM D256, ASTM D790 and ASTM D648 standards were injection molded in a Fluidmec $\mathrm{H} 30 / 40$ at $60-70^{\circ} \mathrm{C}$. Neat PCL specimens were injected using the same procedure for means of comparison ${ }^{15}$.

Compounds studied in this work were named as PCL/ Cotton linter (1\%), PCL/Cotton linter (3\%), PCL/Cotton linter (5\%), PCL/Cotton nanolinter (1\%), PCL/Cotton nanolinter $(3 \%), \mathrm{PCL} /$ Cotton nanolinter $(5 \%)$, in parenthesis is cotton linter and cotton nanolinter content by weight.

\subsubsection{Characterization}

\subsubsection{Lignocellulosic analysis}

The content of moisture, ash, extractives, lignin, hemicellulose, and alpha-cellulose was measured in the raw cotton linter samples applying the procedure reported elsewhere ${ }^{14}$.

\subsubsection{Particle size and zeta potential measurements}

Particle size carried out by dynamic light scattering and potential zeta measurements were done using a Zetasizer Nano ZS (Malvern).

\subsubsection{X-ray diffraction (XRD)}

$\mathrm{X}$-ray diffraction (XRD) experiments were executed in a Shimadzu XRD-6000 instrument in the region of 2-30 $(2 \theta)$, with $\mathrm{K}_{\alpha \mathrm{Cu}}$ radiation, tension $40 \mathrm{kV}$, current $30 \mathrm{~mA}$ and scan rate $2 \% \mathrm{~min}$. 


\subsubsection{Torque rheometry}

Neat PLC, PLC/Cotton linter and PLC/Cotton nanolinter compounds with $1 \%, 3 \%$, and $5 \%$ of cotton linter content, were processed in a HaakeRheomix 600 laboratory internal mixer at $60 \mathrm{rpm}$ for 20 minutes, with the chamber wall kept at $80^{\circ} \mathrm{C}$. Torque and temperature as functions of time were plotted for PCL and its compounds.

\subsubsection{Thermogravimetry (TG)}

Thermogravimetry analyses were performed in a TA Instruments SDT-Q600, samples with $5 \mathrm{mg}$ were heated at $10^{\circ} \mathrm{C} / \mathrm{min}$ from ambient temperature $\left(23^{\circ} \mathrm{C}\right)$ to $1000^{\circ} \mathrm{C}$ under nitrogen flow of $50 \mathrm{~mL} / \mathrm{min}$.

\subsubsection{Differential Scanning Calorimetry (DSC)}

DSC analyses carried out in a Shimadzu DSC-50, samples with approximately $5 \mathrm{mg}$ were heated from $23^{\circ} \mathrm{C}$ to $80^{\circ} \mathrm{C}$, followed by an isothermal stage of 3 minutes and then cooled to $10^{\circ} \mathrm{C}$, with a heating/cooling rate $10^{\circ} \mathrm{C} / \mathrm{min}$, under nitrogen flow of $50 \mathrm{~mL} / \mathrm{min}$.

\subsubsection{Heat deflection temperature (HDT)}

Heat deflection temperature tests carried out in a HDT 6 VICAT P/N 6921.000 instrument according to ASTM D648. Experiments were conducted at load $455 \mathrm{kPa}$, heating rate $120^{\circ} \mathrm{C} / \mathrm{h}(\operatorname{method} \mathrm{A})$, specimens were immersed into silicone bath oil and HDT was determined at $0.25 \mathrm{~mm}$ of specimen deflection. Presented results are the average of five tests.

\subsubsection{Mechanical tests}

Mechanical properties in tension were measured according to ASTM D638; tests were conducted in an EMIC DL 10000 testing machine operating at $50 \mathrm{~mm} / \mathrm{min}$ elongation rate and $200 \mathrm{kgf}$ load. Presented results are an average of ten tests.

Mechanical properties in flexion were measured according to ASTM D790, tests were executed in a universal machine Shimadzu AG-X 50KN with cell charge $20 \mathrm{kN}$, operating at $5 \mathrm{~mm} / \mathrm{min}$ and initial force $29 \mathrm{~N}$. Presented results are an average of five tests.

Mechanical properties in impact were measured according to ASTM D256, tests were performed in a CEAST Resil-5.5 impact machine operating with a $2.75 \mathrm{~J}$ pendulum on notched specimens in Izod configuration. Presented results are an average of ten tests.

All mechanical tests were executed in ambient temperature $\left(23^{\circ} \mathrm{C}\right)$

\subsubsection{Scanning electron microscopy (SEM)}

Scanning electron microscopy images were acquired in a SSX 550 Superscan-Shimadzu. Fractured surface from impact test was covered with gold to avoid accumulation of charges.

\section{Results and Discussion}

\subsection{Lignocellulosic analysis}

Table 1 shows cotton linter components determined by lignocellulosic analysis. Cotton linter presented low levels of humidity, ash and lignin, whereas a high content of cellulose was reached. Based on these data and according to literature cotton linter can be assumed as a promising material to make the PCL compounds ${ }^{16-19}$.

Table 1: Lignocellulosic composition of cotton linter.

\begin{tabular}{lc}
\hline Components & Percentage (\%) \\
\hline Humidity & $5,3 \pm 0,1$ \\
Ash & $1,5 \pm 0,0$ \\
Lignin & $5,9 \pm 0,0$ \\
Holocellulose* & $87,5 \pm 1,2$ \\
Alpha-cellulose & $83,9 \pm 0,6$ \\
Hemicellulose & $3,6 \pm 0,6$ \\
\hline
\end{tabular}

\subsection{Particle size and zeta potential measurements}

Potential zeta measurement was done to verify if cotton nanolinter trends to flocculate, results of potential zeta and particle size are shown in Table 2. Negative value (-50 $\mathrm{mV}$ ) obtained probably is due to hydroxyl esterification of carbohydrates with sulfate groups, which are anionic; with this value in modulus higher than $25 \mathrm{mV}$, the nanocellulose solution can be assumed as stable, meaning it doesn't have a tendency to flocculate ${ }^{14,20}$.

Table 2: Zeta potential, particle size and yielding of nanocrystals of cotton linter.

\begin{tabular}{lc}
\hline Zeta PotentiaL $(\mathrm{mV})$ & $-50,0$ \\
\hline Percentage of particles, < $100 \mathrm{~nm}(\%)$ & 7,2 \\
Average particle size, $<100 \mathrm{~nm}(\mathrm{~nm})$ & 89,7 \\
Percentage of particles, 100-1000 nm (\%) & 92,2 \\
Average particle size, 100-1000 nm (nm) & 319,5 \\
Yielding (\%) & 29,4 \\
\hline
\end{tabular}

Regarding particle size evaluation, $92.2 \%$ of it is between 100-1000 $\mathrm{nm}$ and these were cotton nanolinter particles used in this work. According to yielding results for each kilo of cotton linter subjected to acid hydrolysis, 294 grams of cotton nanolinter are produced.

\subsection{X ray diffraction (XRD) measurements}

Figure 2 shows $\mathrm{X}$ ray diffratograms of PCL, cotton linter, cotton nanolinter, and $\mathrm{PCL} /$ cotton linter and $\mathrm{PCL} /$ cotton nanolinter compounds.

PCL presented peaks around $21.1^{\circ}$ and $23.5^{\circ}$ corresponding to basal distance of $0.42 \mathrm{~nm}$ and $0.38 \mathrm{~nm}$ for the 110 and 200 planes $^{21-24}$. 

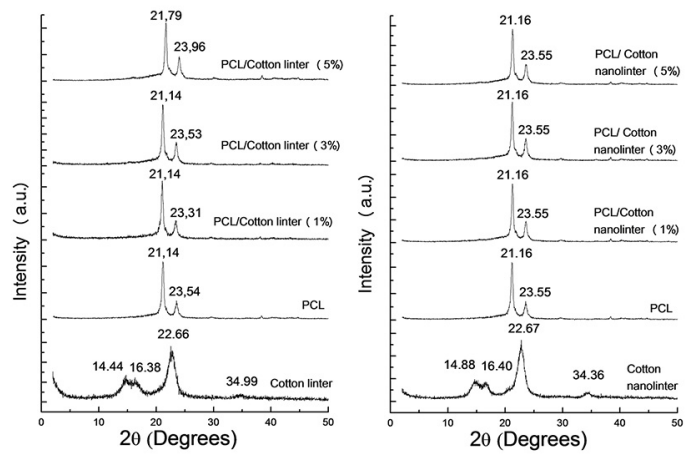

Figure 2: $\mathrm{X}$ ray diffratograms cotton linter, cotton nanolinter, PCL, $\mathrm{PCL} /$ cotton linter and PCL/cotton nanolinter compounds. Cotton linter and its compounds (a), Cotton nanolinter and its compounds (b) (Compositions indicated).

Cotton linter and cotton nanolinter presented peaks around $14.44^{\circ}, 16.38^{\circ}, 22.66^{\circ}$ e $34.99^{\circ}$, corresponding to basal distance of $0.31 \mathrm{~nm}, 0.27 \mathrm{~nm}, 0.20 \mathrm{~nm}$ and $0.13 \mathrm{~nm}$. According to literature they are evidences of cellulose type I and may be attributed to (101), (101), (002) and (004) planes. These results indicated that acid hydrolysis did not change the crystalline character of cotton linter. Moreover, the crystalline character of PCL didn't change upon addition of cotton linter or cotton nanolinter ${ }^{25-26}$.

\subsection{Torque rheometry measurements}

Torque rheometry was used to investigate the thermal stability of PCL and its compounds with cotton linter and cotton nanolinter during processing. Torque value is directly proportional to the polymer viscosity, at constant processing conditions, namely temperature and rotor speed, results of torque may be understood as an indirect measure of molecular weight. Falling down of torque at constant temperature means decreasing in molecular weight, suggesting that polymer degradation took place during processing. A constant torque plateau indicates the absence of degradation ${ }^{27-28}$.

Figure 3 shows temperature and torque versus time plots for PCL/cotton linter and PCL/cotton nanolinter compounds. PCL and its compounds showed constant temperature and torque plateaus for 20 minutes processing time, with no evidence of degradation.

\subsection{Thermogravimetry (TG) Measurements}

Thermal stability and degradation mechanisms of cotton linter, cotton nanolinter, PCL and its compounds were investigated by thermogravimetry (TG). Figure 4 presents TG and differential thermogravimetry (DTG) plots for the compositions tested in this work.

Cotton linter and cotton nanolinter presented similar behaviour in TG plots, around $100^{\circ} \mathrm{C}$ is observed the first event due to water release corresponding to $8 \%$ of weight loss. A second event is verified around $300^{\circ} \mathrm{C}$, it is observed
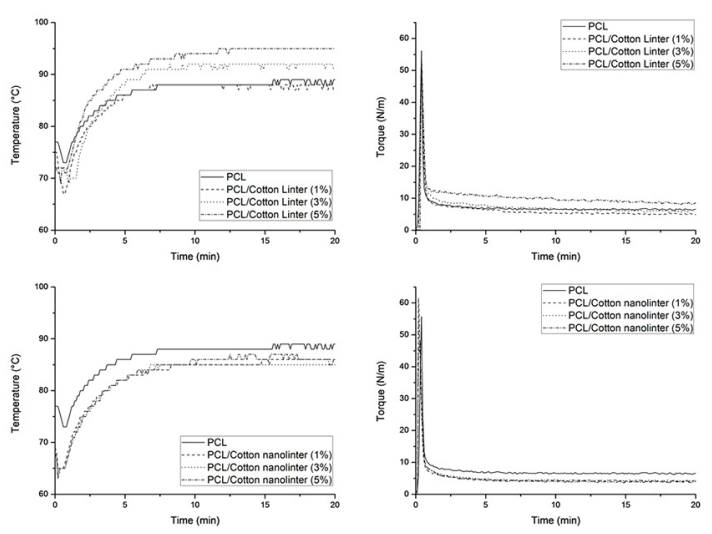

Figure 3: Temperature (left: a and c) and torque (right: $b$ and d) versus time for PCL/cotton linter and PCL/cotton nanolinter compounds. Compositions indicated.
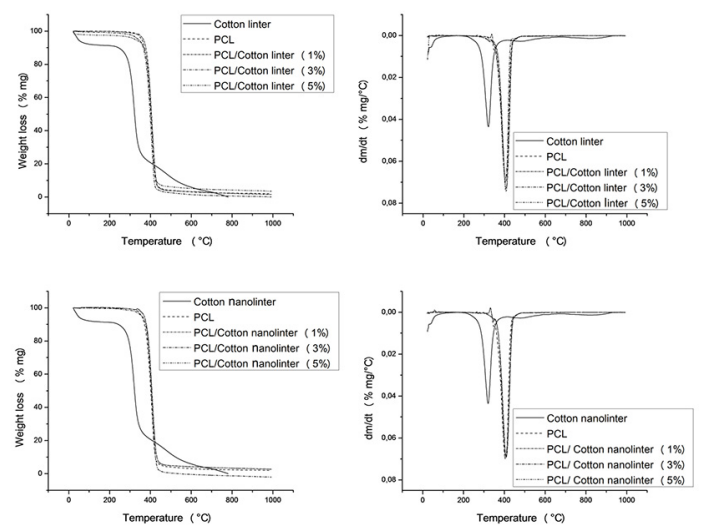

Figure 4: TG and DTG plots for cotton linter, cotton nanolinter, PCL, PCL/cotton linter and PCL/cotton nanolinter compounds. (Compositions indicated).

as a peak between $200^{\circ} \mathrm{C}$ and $400^{\circ} \mathrm{C}$ in DTG plots and it is associated with pyrolysis of cellulose, lignin and hemicellulose and corresponds to $90 \%$ of weight loss. The third event is due to degradation of residual lignin taking place around $700^{\circ} \mathrm{C}$. From TG and DTG plots is verified that the acid hydrolysis did not change the thermal stability of cotton linter ${ }^{29-33}$.

TG plots of PCL presented decomposition in one stage starting around $260^{\circ} \mathrm{C}$, this decomposition is visualized in DTG plots as a peak with maximum height at $405^{\circ} \mathrm{C}$. The residual content at the end of thermal analysis was $2 \%$.

$\mathrm{PCL} /$ cotton linter and $\mathrm{PCL} /$ cotton nanolinter compounds presented TG and DTG plots very similar to that of neat PCL, with plots showing decomposition in one event, the weight loss started around $260^{\circ} \mathrm{C}$ and the maximum degradation rate was observed around $400^{\circ} \mathrm{C}$ in DTG plots. These results mean that the thermal stability of PCL wasn't changed upon addition of cotton linter, although cotton linter has a lower thermal stability compared with PCL. 


\subsection{Differential scanning calorimetry (DSC) measurements}

Figure 5 shows endotherms of fusion and exotherms of melt crystallization for PCL and PCL/cotton linter and PCL/ cotton nanolinter compounds, and Table 3 presents thermal parameters acquired from DSC scans. Apparently, adding cotton linter / cotton nanolinter had mild effect on PCL fusion, all endotherms presented simple peaks indicating that fusion takes place in a single event. Usually, biodegradable polymer as example PHB present complex peaks during fusion due to different morphologies, crystallite sizes and stabilities; however in the present work neither cotton linter nor cotton nanolinter changed the thermal character of PCL. Although the acid hydrolysis to which cotton linter was subjected with the intention of generating new reactive groups and chemical links between PCL and cotton nanolinter, seemingly it was not strong enough to create new populations of crystals ${ }^{34-36}$.

Concerning the crystallization peak, it became narrower and sharper upon filling addition; this result suggests an increase in polymer homogeneity. Higher degree of crystallinity was observed for the compounds with $1 \%$ and $3 \%$ nanolinter. The maximum crystallization peak took place earlier for compounds with nanolinter, an increase around 30\% was observed for this parameter, suggesting the melt crystallization occurred earlier in cotton nanolinter compounds, possible due a nucleant effect. It is known from literature that addition of filling to polymer may result in nucleant effect. It is possible that cotton linter and cotton nanolinter are behaving as nucleant during PCL crystallization. In general, the observed enthalpy of crystallization and the crystallinity results suggest that these parameters were not significantly affected by the presence and concentration of the fillers ${ }^{35,37}$.

\subsection{Mechanical properties evaluation}

Mechanical properties in tension for PCL and its compounds with cotton linter and cotton nanolinter are showed in Figure 6. PCL is a ductile polymer as its elongation
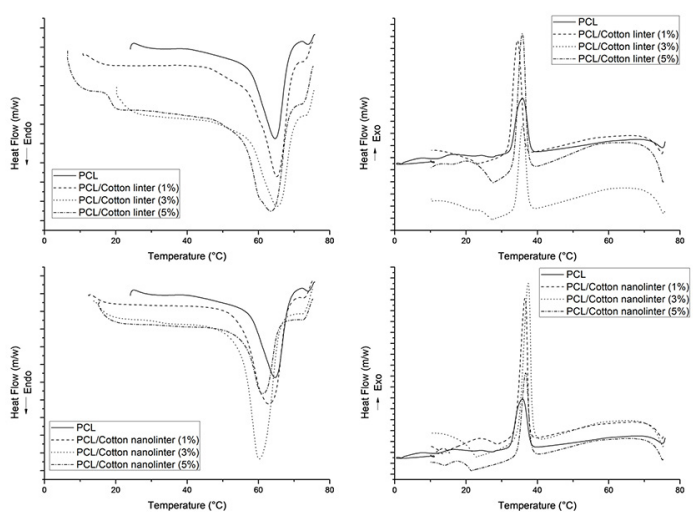

Figure 5: Melt endotherms and Crystallization exotherms for PCL/ cotton linter and PCL/cotton nanolinter compounds. Compositions indicated.

at break was $418.6 \%$, upon addition of cotton linter this property increased to values higher than $430 \%$, and for the compositions with $1 \%$ and $3 \%$ the experiment reached the machine limit without rupture taking place.
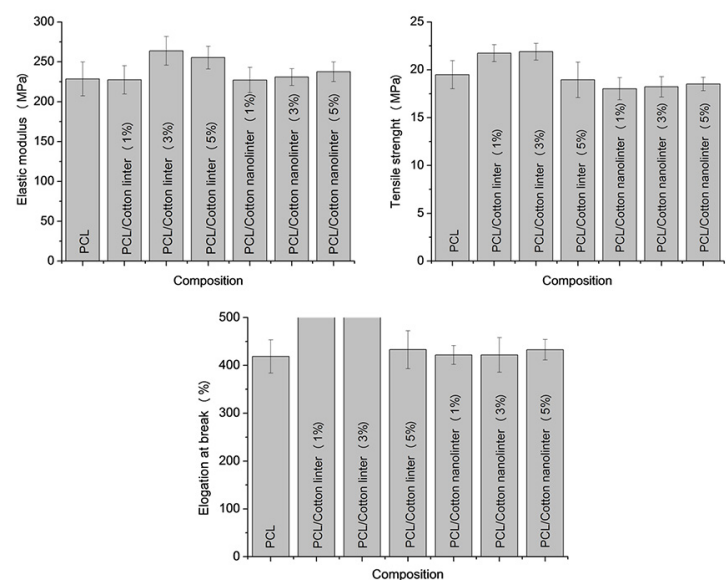

Figure 6: Mechanical properties in tension: Elastic modulus, Tensile strength and Elongation at break of PCL, and PCL/Cotton linter and $\mathrm{PCL} / \mathrm{Cotton}$ nanolinter compounds. Compositions indicated.

Table 3: Characteristic temperatures, enthalpies of fusion and crystallization, and degree of crystallinity for PCL/cotton linter and PCL/ cotton nanolinter compounds.

\begin{tabular}{lccccc}
\hline Compositions & $\mathrm{T}_{\mathrm{m}}\left({ }^{\circ} \mathrm{C}\right)$ & $\Delta \mathrm{H}_{\mathrm{m}}(\mathrm{J} / \mathrm{g})$ & $\mathrm{T}_{\mathrm{c}}\left({ }^{\circ} \mathrm{C}\right)$ & $\Delta \mathrm{H}_{\mathrm{c}}(\mathrm{J} / \mathrm{g})$ & $\mathrm{X}_{\mathrm{c}}(\%)$ \\
\hline PCL & 65.0 & -56.8 & 30.0 & 39.6 & 40.7 \\
PCL/cotton linter (1\%) & 65.5 & -67.2 & 29.9 & 48.3 & 47.7 \\
PCL/cotton linter (3\%) & 65.5 & -55.8 & 29.9 & 40.1 & 38.8 \\
PCL/cotton linter (5\%) & 63.9 & -67.9 & 32.9 & 47.7 & 46.2 \\
PCL/cotton nanolinter (1\%) & 63.2 & -69.9 & 36.6 & 50.8 & 49.6 \\
PCL/cotton nanolinter (3\%) & 60.3 & -78.2 & 38.9 & 59.5 & 54.3 \\
PCL/cotton nanolinter (5\%) & 61.3 & -53.2 & 38.6 & 39.9 & 36.2 \\
\hline
\end{tabular}

$\mathrm{T}_{\mathrm{m}}=$ Temperature of melting peak; $\Delta \mathrm{H}_{\mathrm{m}}=$ Melting enthalpy; $\mathrm{T}_{\mathrm{c}}=$ Temperature of crystallization peak; $\Delta \mathrm{H}_{\mathrm{c}}=$ Enthalpy of crystallization; $\mathrm{X}_{\mathrm{C}}=$ Degree of crystallinity, $\left(\mathrm{X}_{\mathrm{c}}=\frac{\Delta H m}{\Delta H m} x 100\right) ; \Delta \mathrm{H}_{m}^{o}=$ Equilibrium melting enthalpy; $\Delta \mathrm{H}_{m}^{o}=139.5 \mathrm{~J} / \mathrm{g}^{38}$. 
Regarding elastic modulus results, an increase of $12 \%$ and $16 \%$ was observed for the PCL compounds with $3 \%$ and $5 \%$ of cotton linter, compounds with cotton linter $1 \%$ and $3 \%$ presented strength stress increased by $12 \%$. None reasonable effect in tensile properties of adding cotton nanolinter to PCL was verified as presented in Figure 6.

In principle, these results are encouraging, once lower cost filling was added to PCL, promoting an increasing in its thermal stability (HDT, Figure 9), tensile strength and elongation at break (Figure 6). Probably these properties are linked to a well dispersed cotton linter (fibrils) and cotton nanolinter (particles) within the PCL matrix (see SEM images in Figures 13 and 14). That was obtained due to appropriated processing conditions ${ }^{16,39-40}$.
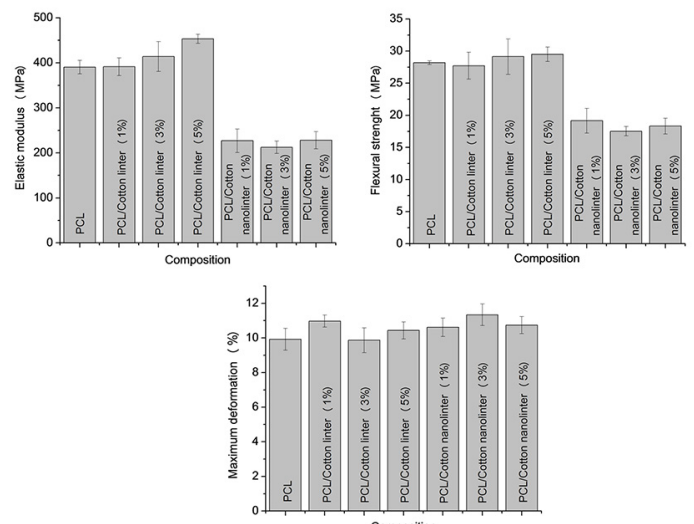

Figure 7: Mechanical properties in flexion: Elastic modulus, Tensile strength and Elongation at break of PCL, and PCL/cotton linter and $\mathrm{PCL} /$ cotton nanolinter compounds. Compositions indicated.

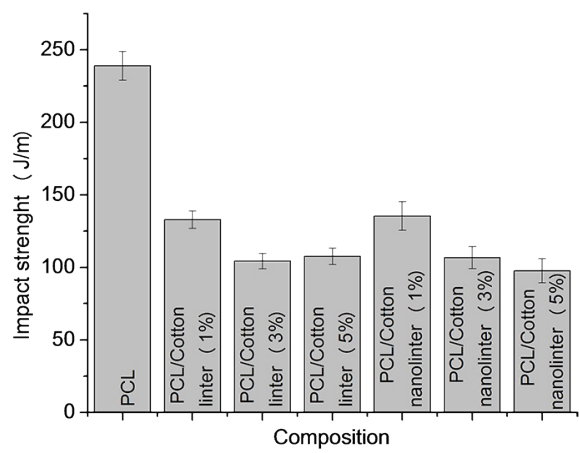

Figure 8: Impact strength of PCL, and PCL/cotton linter and PCL/ cotton nanolinter compounds. Compositions indicated.

Mechanical properties in flexion for PCL and its compounds with cotton linter and cotton nanolinter are showed in Figure 7. Adding nanolinter to PCL decreased its elastic modulus and flexural strength with slight effect on maximum deformation. For three cotton nanolinter contents investigated in this work similar results for flexion experiments

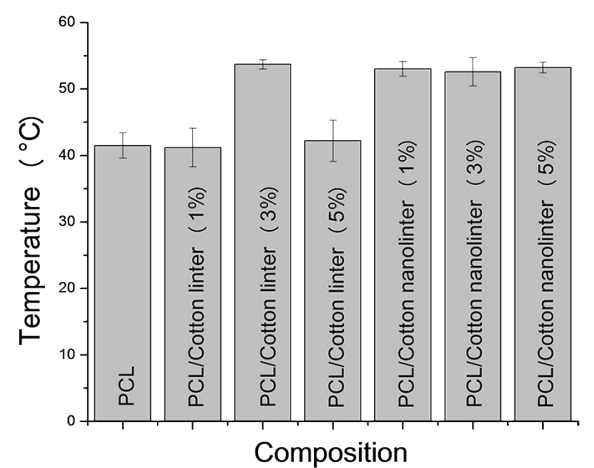

Figure 9: HDT measurements of PCL, PCL/cotton linter and PCL/ cotton nanolinter compounds.

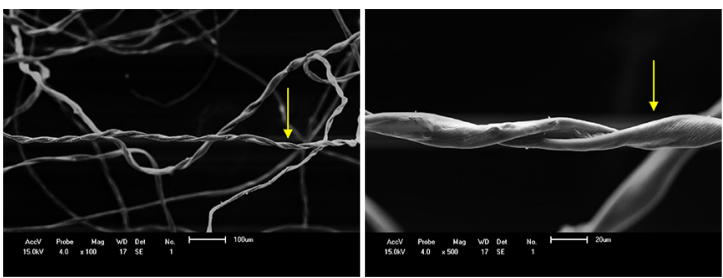

Figure 10: SEM images of Cotton linter fibrils. (Scale bar: 100 $\mu \mathrm{m}$ and $20 \mu \mathrm{m})$.
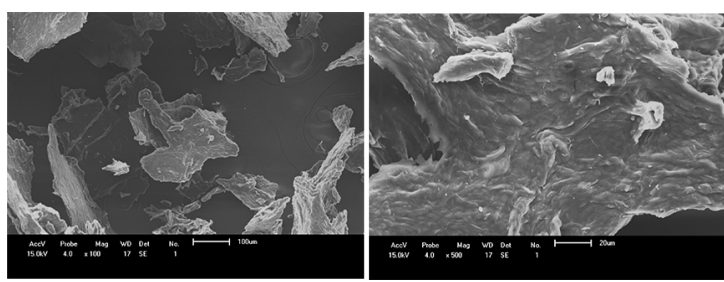

Fgure 11: SEM images of Cotton nanolinter particles. (Scale bar: $100 \mu \mathrm{m}$ and $20 \mu \mathrm{m})$.
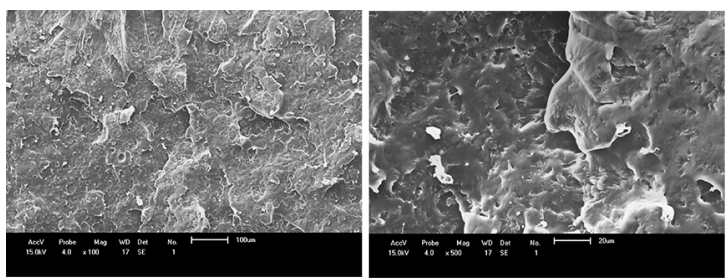

Figure 12: SEM image of fractured surface of PCL. (Scale bar: $100 \mu \mathrm{m}$ and $20 \mu \mathrm{m})$.

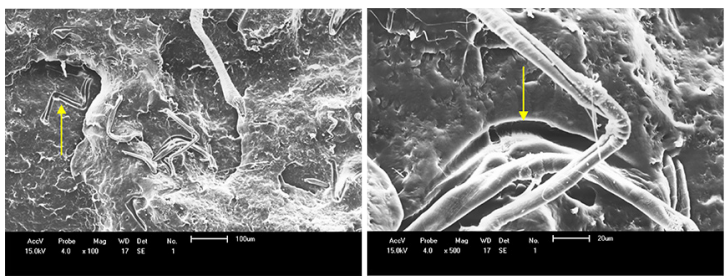

Figure 13: SEM image of fractured surface of PCL/cotton linter (1\%). (Scale bar: $100 \mu \mathrm{m}$ and $20 \mu \mathrm{m}$ ). 


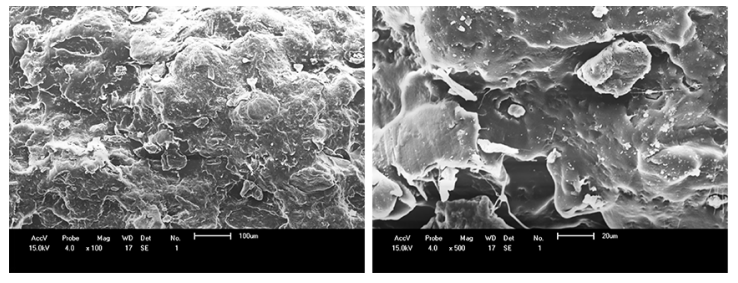

Figure 14: SEM image of fractured surface of PCL/cotton nanolinter (5\%). (Scale bar: $100 \mu \mathrm{m}$ and $20 \mu \mathrm{m}$ ).

were obtained. Nevertheless, increases of $6 \%$ and $16 \%$ were observed in elastic modulus of PCL/cotton linter (3\%) and $\mathrm{PCL} /$ cotton linter (5\%) compounds, respectively, whereas no change was verified in flexural strength and maximum deformation for PCL compounds with cotton linter. The reduction in the Elastic Modulus, Flexural Strength and Impact Strength (see Figure 8) of nanolinter compounds compared with conventional cotton linter compounds may be explained in part by possible increase of tension concentration regions originated the nanoparticles as well as by aggregation mechanisms. Flexion experiments may be used to define bending tolerance of polymer products; for this specific use compounds with cotton linter should be chosen instead of cotton nanolinter compounds.

Mechanical properties in impact for PCL and its compounds with cotton linter and cotton nanolinter are showed in Figure 8. All compounds processed in this work presented lower impact strength than neat PCL, decreases of $59 \%, 55 \%$ and $43 \%$ were acquired for compositions with $1 \%, 3 \%$ and $5 \%$ of cotton nanolinter; and decreases of $55 \%$, $56 \%$ and $44 \%$ were acquired for compositions with $1 \%$, $3 \%$ and $5 \%$ cotton linter. PCL as showed above is a ductile polymer with higher impact strength.

Impact strength is a measurement of energy dissipation during short term deformation in polymeric solids. It is believed that in PCL compounds the added fibrils and particles may be acted as stress concentrators hindering the energy dissipation mechanisms to work properly thus lowering the impact strength.

\subsection{Heat deflection temperature (HDT) measurements}

Figure 9 presents HDT results for PCL and its compounds with cotton linter and cotton nanolinter. Compounds upon addition of cotton nanolinter presented temperatures approximately $20 \%$ higher than neat PCL and PCL/cotton linter compounds. In general, adding natural fibers to polymers increases its brittle character, normally changing its strain behavior; an interesting result obtained in this work was the increase in HDT values of cotton nanolinter compounds with no change in strain at break values (see Figure 6). This increase in HDT values indicates that the acid hydrolysis was successful, and may result in an increase in the use temperature of PCL products ${ }^{39,41-42}$.
It was not observed significant difference in mechanical and thermal properties between nanolinter and conventional linter compounds. Consequently, the use of the more expensive, chemically modified filler is not justified.

\subsection{Scanning Electron Microscopy (SEM) Images}

SEM images of cotton linter used in this work to make PCL compounds are shown in Figure 10. It presented an interlacing fibril structure with high L/D (length/diameter) ratio. In Figure 11 is showed images of cotton nanolinter, a drastic structural change is verified, provoked by acid hydrolysis; cotton nanolinter show a particulate structure with some aggregates; although the acid hydrolysis didn't change the crystalline and thermal character of cotton linter (see Figures 2, 4 and 5) it modified its morphological structure.

Figure 12 shows SEM images of PCL that presents a ductile fracture with several zones of plastic deformation, which agrees with strain results shown in Figure 6.

Figure 13 presents SEM images of PCL/cotton linter (1\%). Clearly, a matrix/fibrils morphology could be seen; upon fracture some fibrils remained attached to PCL matrix while others were detached from it. In general cotton linters fibrils were well dispersed in PCL matrix promoting the good properties of PCL compounds as mentioned above.

SEM images of PCL/cotton nanolinter (5\%) are showed in Figure 14. A particulate structure embedded within PCL matrix is verified, the acid hydrolysis to which raw cotton linter was subjected changed it shape from fibrils to particle as earlier described. This structure is easily observed in Figure 14. Particle aggregates were obtained probably due to the lower miscibility between PCL and cotton nanolinter; however, they weren't strong enough to compromise the mechanical performance and thermal stability of PCL, as mechanical (Figure 6) and HDT (Figure 9) results showed.

\section{Conclusions}

PCL/cotton linter and nanolinter compounds studied in this work showed properties similar to neat PCL. Higher ductility was reached in compounds with cotton linter whereas higher HDT was got in nanolinter systems, suggesting the possibility of higher use temperature. The increase in the crystallization temperature suggests shorter processing time. Filers are less expensive than the matrix thus the researched compounds present attractive alternative to neat PCL.

\section{Acknowledgments}

The authors are indebted to CNPq and Capes (Brasilia/ DF, Brazil) for the financial support; to Embrapa Algodão, Campina Grande/Paraíba/Brazil for supplying the raw cotton, to Embrapa Agroindústria Tropical, Fortaleza/Ceará/Brazil 
for supplying the cotton nanolinter, and to Federal University of São Carlos Polymer Laboratory for HDT experiments.

\section{References}

1. Philp JC, Bartsev A, Ritchie RJ, Baucher MA, Guy K. Bioplastics science from a policy vantage point. New Biotechnology. 2013;30(6):635-646.

2. Sorrentino A, Gorrasi G, Vittoria V. Potential perspectives of bio-nanocomposites for food packaging applications. Trends in Food Science \& Technology. 2007;18(2):84-95.

3. Ludueña LN, Alvarez VA, Vazquez A. Processing and microstructure of PCL/clay nanocomposites. Materials Science and Engineering: A. 2007;460-461:121-129.

4. Wang YW, Mo W, Yao H, Wu Q, Chen J, Chen GQ. Biodegradation studies of poly(3-hydroxybutyrate-co-3-hydroxyhexanoate). Polymer Degradation and Stability. 2004;85(2):885-891.

5. Bucci DZ, Tavares LBB, Sell I. Biodegradation and physical evaluation of PHB packaging. Polymer Testing. 2007;26(7):908-915.

6. Falcone DMB, Agnelli JAM, Faria LIL. Panorama setorial e perspectivas na área de polímeros biodegradáveis. Polímeros: Ciência e Tecnologia. 2007;17(1):5-9.

7. Ludueña LN, Vázquez A. Alvarez VA Effect of lignocellulosic filler type and content on the behavior of polycaprolactone based eco-composites for packaging applications. Carbohydrate Polymers, 2012; 87, 411-421.

8. Larrañaga A, Aldazabal P, Martin FJ, Sarasua JR. Hydrolytic degradation and bioactivity of lactide and caprolactone based sponge-like scaffolds loaded with bioactive glass particles. Polymer Degradation and Stability. 2014;110:121-128.

9. Castilla-Cortázar I, Más-Estellés J, Meseguer-Dueñas JM, Escobar Ivirico JL, Marí B, Vidaurre A, Vidaurre A. Hydrolytic and enzymatic degradation of a poly( $\varepsilon$-caprolactone) network. Polymer Degradation and Stability. 2012;97(8):1241-1248.

10. Cunha AJ. Fibra Natural de Algodão Modificada com Ácido Citrico: um Biossorvente para Metais Pesados. [MSc Dissertation]. Londrina: Universidade Federal de Londrina; 2010.

11. Morgado DL. Biocompósitos a partir de celulose de línter: filmes de acetatos de celulose/celulose e quitosana/celulose. [Doctoral Thesis]. São Carlos: Universidade de São Paulo, Instituto de Química de São Carlos; 2009.

12. Vieira RM, Beltrão NEM, Lima RLS, Leão AB. Produção de sementes do algodoeiro. In: Beltrão NEM, Azevedo DMP, eds. O Agronegócio do Algodão no Brasil. Brasília: Embrapa Informação Tecnológica; 2008. p. 509-533.

13. Zhao H, Kwak JH, Zhang C, Brown HM, Arey BW, Holladay JE. Studying cellulose fiber structure by SEM, XRD, NMR and acid hydrolysis. Carbohydrate Polymers. 2007;68(2):235-241.

14. Morais JPS, Rosa MF, Souza Filho MSM, Nascimento LD, Nascimento DM, Cassales AR. Extraction and characterization of nanocellulose structures from raw cotton linter. Carbohydrate Polymers. 2013;91(1):229-235.

15. Bezerra EB. Obtenção de sistemas de PCL com subproduto da cultura algodoeira [MSc Disserrtation]. Campina Grande: Universidade Federal de Campina Grande; 2014.
16. Corradini E, Rosa MF, Macedo BP, Paladin PD, Mattoso LHC. Composição química, propriedades mecânicas e térmicas da fibra de frutos de cultivares de coco verde. Revista Brasileira de Fruticultura. 2009;31(3):837-846.

17. Pereira H, Graça J, Rodrigues JC. Wood chemistry in relation to quality. In: Barnett JR, Jeronimidis G, ed. Wood quality and its biological basis. Boca Raton: CRC Press; 2003. p. 53-86.

18. Tita SPS, Paiva JMF, Frollini E. Resistência ao impacto e outras propriedades de compósitos lignocelulósicos: matrizes termofixas fenólicas reforçadas com fibras de bagaço de cana-de-açúcar. Polímeros: Ciência e Tecnologia. 2002;12(4):228-239.

19. Schniewind AP, Berndt $H$. The composite nature of wood. In: Lewin M, Goldstein IS, Dekker M, ed. Wood structure and composition. New York: Marcel Dekker; 1991. p. 435-476.

20. Mirhosseini H, Tan CP, Hamid NSA, Yusof S. Effect of Arabic gum, xanthan gum and orange oil contents on $\zeta$-potential, conductivity, stability, size index and $\mathrm{pH}$ of orange beverage emulsion. Colloids and Surfaces A: Physicochemical and Engineering Aspects. 2008;315(1-3):47-56.

21. Gautam S, Dinda AK, Mishra NC. Fabrication and characterization of PCL/gelatin composite nanofibrous scaffold for tissue engineering applications by electrospinning method. Materials Science and Engineering: C. 2013;33(3):1228-1235.

22. Jiang S, Ji X, An L, Jiang B. Crystallization behavior of PCL in hybrid confined environment. Polymer. 2001;42(8):3901-3907.

23. Kim HW, Knowles JC, Kim HE. Hydroxyapatite/poly( $\varepsilon-$ caprolactone) composite coatings on hydroxyapatite porous bone scaffold for drug delivery. Biomaterials. 2004;25(7-8):1279-1287.

24. Vertuccio L, Gorrasi G, Sorrentino A, Vittoria V. Nano clay reinforced PCL/starch blends obtained by high energy ball milling. Carbohydrate Polymers. 2009;75(1):172-179.

25. Saha P, Manna S, Sen R, Roy D, Adhikari B. Durability of lignocellulosic fibers treated with vegetable oil-phenolic resin. Carbohydrate Polymers. 2012;87(2):1628-1636.

26. Adel AM, El-Wahab ZHA, Ibrahim AA, Al-Shemy MT. Characterization of microcrystalline cellulose prepared from lignocellulosic materials. Part I. Acid catalyzed hydrolysis. Bioresource Technology. 2010;101(12):4446-4455.

27. França DC. Avaliação do comportamento de degradação da PCL $e$ de sistemas PCL/argila sob condições ambientais severas. [MSc Dissertation]. Campina Grande: Universidade Federal de Campina Grande; 2014.

28. Manas-Zloczower I. Mixing and compounding of polymers: theory and practice. $2^{\text {nd }}$ ed. Munich \& Cincinnati: Hanser; 2009.

29. Cho MJ, Park BD. Tensile and thermal properties of nanocellulosereinforced poly(vinyl alcohol) nanocomposites. Journal of Industrial and Engineering Chemistry. 2011;17(1):36-40.

30. Abraham E, Elbi PA, Deepa B, Jyotishkumar P, Pothen LA, Narine SS, et al. X-ray diffraction and biodegradation analysis of green composites of natural. Polymer Degradation and Stability. 2012;97(11):2387-2378.

31. Mandal A, Chakrabarty D. Isolation of nanocellulose from waste sugarcane bagasse (SCB) and its characterization. Carbohydrate Polymers. 2011;86(3):1291-1299. 
32. Morán JI, Alvarez VA, Cyras VP, Vázquez A. Extraction of cellulose and preparation of nanocellulose from sisal fibers. Cellulose. 2008;15(1):149-159.

33. Rosa MF, Medeiros ES, Malmonge JA, Gregorski KS, Wood DF, Mattoso LHC, et al. Cellulose nanowhiskers from coconut husk fibers: Effect of preparation conditions on their thermal and morphological behavior. Carbohydrate Polymers. 2010;81(1):83-92.

34. Wellen RMR, Rabello MS, Fechine GJM, Canedo EL. The melting behaviour of poly(3-hydroxybutyrate) by DSC. Reproducibility study. Polymer Testing. 2013;32(2):215-220.

35. Wellen RMR, Canedo EL, Rabello MS. Melting and crystallization of poly(3-hydroxybutyrate)/carbon black compounds. Effect of heating and cooling cycles on phase transition. Journal of Materials Research. 2015;30(21):3211-3226

36. Vitorino MBC, Reul LT, Wellen RMR, Canedo EL, Carvalho LH. Nonisothermal melt crystallization of PHB/Babassu compounds. Part I: Crystallization parameters. Journal of Thermal Analysis and Calorimetry. 2015. (Submitted)

37. Wellen RMR, Rabello MS, Araujo Júnior IC, Fechine GJM, Canedo EL. Melting and crystallization of poly(3-hydroxybutyrate). Effect of heating/cooling rates on phase transformation. Polimeros Ciência e Tecnologia. 2015;25(3):296-304.
38. Eldsäter C, Erlandsson B, Renstad R, Albertsson AC, Karlsson $\mathrm{S}$. The biodegradation of amorphous and crystalline regions in film-blown poly( $\epsilon$-caprolactone). Polymer. 2000;41(4):1297-1304.

39. Borsoi C, Scienza LC, Zattera AJ, Angrizani CC. obtenção e caracterização de compósitos utilizando poliestireno como matriz e resíduos de fibras de algodão da indústria têxtil como reforço. Polímeros: Ciência e Tecnologia. 2001;21(4):271-279.

40. Marinelli AL, Monteiro MR, Ambrósio JD, Branciforti MC, Kobayashi M, Nobre AD. Desenvolvimento de Compósitos Poliméricos com Fibras Vegetais Naturais da Biodiversidade: Uma Contribuição para a Sustentabilidade Amazônica. Polímeros: Ciência e Tecnologia. 2008;18(2):92-99.

41. García M, Garmendia I, García J. Influence of natural fiber type in eco-composites. Journal Applied Polymer Science. 2008;107(5):2994-3004.

42. Vianna WL, Correa CA, Razzino CA. Efeitos do tipo de poliestireno de alto impacto nas propriedades de compósitos termoplásticos com farinha de resíduo de madeira. Polímeros: Ciência e Tecnologia. 2004;14(5):339-348. 